\title{
The Evaluation of Financial Innovation Ability of Listed Banks in China Based on Factor Analysis
}

\section{Feng Zilin Shi Ruo}

\author{
School of Finance, Guizhou University of Finance and Economics, Guiyang Guizhou \\ 550025, China
}

\begin{abstract}
Commercial Banks is the core part of the financial system in China, and in the development of commercial Banks can innovation Force of a direct impact on the market competitiveness of commercial Banks. This paper starting from the basic theory of financial innovation, the main part is separately from the financial business innovation ability, finance, science and technology innovation ability, finance, human resources innovation ability and financial risk management innovation ability four aspects included 4 first-level indicators, 11 second-level indicators to build commercial bank financial innovation ability evaluation index system, using factor analysis method to evaluate to the our country commercial bank financial innovation ability. Finally, combined with the results of the empirical analysis of China's listed commercial Banks to improve its financial innovation ability put forward corresponding countermeasures.
\end{abstract}

Key words

Listed Commercial Banks; Financial Innovation Ability; Factor Analysis

\section{基于因子分析的我国上市银行金融创新 能力评价研究}

\author{
冯紫琳 施若 \\ 贵州财经大学金融学院, 花溪, 贵阳, 贵州 550025, 中国
}

摘要：商业银行是我国金融体系的核心组成部分，而金融创新能力的高低对商业银行的市场 竞争力产生直接的影响。本论文从金融创新的理论基础出发，主要部分是分别从金融业务创 新能力、金融科技应用创新能力、金融人力资源管理创新能力及金融风险管理创新能力四个 方面选取 4 个一级指标, 11 个二级指标构建商业银行金融创新能力评价指标体系, 采用因 子分析法对我国商业银行金融创新能力进行评价。最后, 结合实证分析的结果, 对我国上市 商业银行提升其金融创新能力提出相应的对策措施。

关键词: 上市商业银行; 金融创新能力; 因子分析法 


\section{1. 引言}

随着互联网金融的冲击，金融科 技的发展，传统商业银行要么提高自 身的金融创新能力, 要么同科技企业 合作寻求共赢。另一方面，在市场竞 争加剧、利率市场化、金融脱媒、监 管强化以及资本压力加大的背景下, 商业银行只有加大金融创新力度, 才 能满足客户日渐多样化和个性化的需 求, 才能在竞争中保持优势地位。目 前关于银行金融创新和银行核心竞争 力的评价研究比较丰富, 很少有对金 融机构金融创新的表现出发, 研究影 响金融创新的绩效的因子。因此, 构 建一个明确的商业银行金融创新力评 价指标体系，可以为我国上市商业银 行提供金融创新能力所涉及的要素和 内容进行改善, 并对它们了解自身在 行业中的地位和如何提高自身的竞争 力具有现实意义。

\section{2. 文献综述}

David Llewellyn (1985) 认为金 融创新是指各种金融工具的运用、新 金融市场的产生和金融服务方式的发 展。

J. R. Hicks, J.Mehans (1994) 认为降低交易成本是金融创新的原 因，金融创新活动的交易成本的高低 决定了金融活动的实际价值。

Akhavein, Frame 和 White (2001) 对 20 世纪 90 年代的银行小额 商业贷款信用评分系统做了调查研 究, 结果显示大银行引进金融创新较 早, 也发现那些子银行数量较少、分 行数量较多的银行引入金融创新也较 早。

夏婷，肖科 (2006) 通过数据分析 得出我国国有商业银行金融创新能力 水平是人均利润与人均金融资产占有
量之间的比值, 并与国有银行经营效 率高度正相关。

张健 (2008) 以区域金融理论和金 融创新理论为基础, 界定了区域金融 创新能力的概念和特征, 运用灰色关 联度法对黑龙江省区域金融创新能力 进行了实证分析，提出通过改善金融 生态环境、推动金融制度创新、建立 健全多层次金融市场体系、拓展金融 产品种类和提高金融资源配置效率等 措施来提升黑龙江省区域金融创新能 力。

曹蒸蒸（2009）分析了我国商业 银行的金融创新现状并界定了金融创 新力, 然后通过选取 14 家商业银行作 为研究对象, 构建了我国商业银行金 融创新力的评价指标体系, 利用主成 分分析法对这些银行的金融创新力进 行了实证分析, 并做出相应的综合评 价。

刘铁锤（2013）结合对西方商业银 行金融创新的研究和国家控股商业银 行的现实, 阐述了国家控股商业银行 金融创新的战略意义，分析了国家控 股商业银行创新不足的问题, 提出了 经营理念、组织机构、经营机制、人 力资源管理、经营业务等金融创新的 现实选择。

任婉璐（2015）选取 2006 -2013 年中国五大国有银行年报数据, 使用 Eviews 软件对影响国有银行金融创新 的各因素进行相关性分析。得出净息 差与资本充足率对银行创新能力有着 显著地影响, 而其他因素对银行创新 能力影响不大的结果，并针对金融创 新体系提出了中间业务创新、加强风 控能力、深化创新水平、改革产权制 度模式等政策建议。

陈雅慧（2017）通过构建商业银 行金融业务创新能力、金融技术水平 创新能力以及金融创新风险控制能力 三个一级指标, 并利用实数编码的 
RAGA-PPC 模型, 对 2016 年五大国有银 行进行金融创新能力实证分析。

普加丽（2017）构建了互联网金 融业务创新、科技应用创新、人力资 源创新、风险管理创新等四大类指标 组成的中国银行互联网金融创新能力 评价体系，以建设银行为典型样本， 采用因子分析法对其金融创新能力进 行实证分析。

\section{3. 我国上市商业银行金融创新能力的 实证分析}

\section{1. 指标体系的建立}

结合指标体系五项基本原则，参 考国内外相关的研究成果, 根据国内 上市银行金融创新的现状，按照创新 对象进行分类, 商业银行的金融创新 具体分为金融业务创新、科技应用创 新、人力资源管理创新及风险管理创 新四个方面。具体指标如表 1 所示:

表 1 指标体系的构建

\begin{tabular}{ccc}
\hline 评价指标 & 一级指标 & 二级指标 \\
\hline & & 手续费及佣金净收入 X1 \\
& 手续费及佣金净收入占 \\
& 金融业务 & 营业收入比 X2 \\
& 创新能力 & 手续费及佣金净收入增 \\
商业银行 & & 长率 X3 \\
金融创新 & 金融科技 & 信用卡发行量 X5 \\
能力 & 创新能力 & 网点数 X6 \\
& 金融人力 & 人均净利润 X7 \\
& 资源管理 & 本科及以上学历占比 X8 \\
& 创新能力 & \\
& 金融风险 & 不良贷款率 X9 \\
& 管理创新 & 流动比率 X10 \\
& 能力 & 资本充足率 X11 \\
\hline
\end{tabular}

\section{2. 数据来源}

样本数据主要来源于 16 家上市商 业银行 2016 年年报。各银行分别是中 国工商银行、中国银行、中国建设银 行和交通银行, 招商银行、交通银
行、中信银行、平安银行、光大银 行、民生银行、浦发银行、兴业银 行、华夏银行, 北京银行、南京银行 和宁波银行。

表 216 家上市商业银行的原始数据

\begin{tabular}{|c|c|c|c|c|c|}
\hline & $\begin{array}{l}\text { 手续费 } \\
\text { 及佣金 } \\
\text { 净收入 } \\
\text { X1（百 } \\
\text { 万） }\end{array}$ & $\begin{array}{c}\text { 手续费 } \\
\text { 及佣金 } \\
\text { 净收入 } \\
\text { 占比 X2 } \\
(\%)\end{array}$ & $\begin{array}{l}\text { 手续费 } \\
\text { 及佣金 } \\
\text { 净收入 } \\
\text { 增长率 } \\
\text { X3(\%) }\end{array}$ & $\begin{array}{c}\text { 成本收 } \\
\text { 入比 X4 } \\
(\%)\end{array}$ & $\begin{array}{c}\text { 信用卡 } \\
\text { 发卡量 } \\
\text { X5（万 } \\
\text { 张） }\end{array}$ \\
\hline 中国 & 88664 & 18.33 & 4.05 & 28.08 & 5399 \\
\hline 农业 & 60635 & 17.97 & 10.15 & 34.59 & 6863 \\
\hline 工商 & 144973 & 21.45 & 1. 10 & 25.91 & 11779 \\
\hline 建设 & 118509 & 19.59 & 4. 39 & 27.49 & 9407 \\
\hline 民生 & 52261 & 33.67 & 2.06 & 30.98 & 2834 \\
\hline 浦发 & 40692 & 25.30 & 46.38 & 23. 16 & 2758 \\
\hline 招商 & 60865 & 29. 12 & 14.82 & 28.01 & 8031 \\
\hline 平安 & 27859 & 25.86 & 15.68 & 25.97 & 838 \\
\hline 交通 & 36795 & 19.05 & 5.05 & 31.6 & 5043 \\
\hline 兴业 & 36552 & 23.27 & 15.15 & 23.39 & 2082 \\
\hline 华夏 & 14656 & 22.89 & 18.46 & 34.5 & 1154 \\
\hline 光大 & 28112 & 29.89 & 6.89 & 28.77 & 3596 \\
\hline 中信 & 42280 & 27.49 & 18.52 & 27.56 & 3738 \\
\hline 北京 & 9599 & 20.23 & 34.82 & 25.81 & 268 \\
\hline & 3822 & 14. 36 & 17. 49 & 24.8 & 17 \\
\hline 宁波 & 6047 & 25.57 & 51.56 & 34.26 & 128 \\
\hline
\end{tabular}

续表 216 家上市商业银行的原始数据

\begin{tabular}{|c|c|c|c|c|c|c|}
\hline & \multicolumn{3}{|c|}{ 人均净本科以 } & \multicolumn{3}{|c|}{ 不良贷 流动性 资本充 } \\
\hline & 网点数 & 利润 & 上学历 & 款率 & 比例 & 足率 \\
\hline & X6 & $\mathrm{X} 7$ & 口比 & X9 & X10 & X11 \\
\hline & & （万） & $\begin{array}{l}x 8 \\
(\%)\end{array}$ & & $(\%)$ & $(\%)$ \\
\hline 中国 & 10978 & 23.03 & 71.06 & 1. 46 & 45.6 & 14. 28 \\
\hline 农业 & 23682 & 18.60 & 49.2 & 2. 37 & 46.74 & 13. 04 \\
\hline 工商 & 16788 & 30.59 & 55.50 & 1. 62 & 35.7 & 14.61 \\
\hline 建设 & 14956 & 32.86 & 64.47 & 1.52 & 44.21 & 14. 94 \\
\hline 民生 & 3003 & 46. 26 & 84.05 & 1. 68 & 39.64 & 11.73 \\
\hline 浦发 & 1843 & 53. 12 & 80.59 & 1.89 & 37.67 & 11.65 \\
\hline 招商 & 1811 & 42.84 & 86.1 & 1.87 & 59.42 & 13. 33 \\
\hline 平安 & 1072 & 22.92 & 81.02 & 1. 74 & 47.62 & 11.53 \\
\hline 交通 & 3285 & 35.87 & 79.76 & 1.52 & 50.92 & 14. 02 \\
\hline 兴业 & 2003 & 49. 28 & 88.14 & 1.65 & 59.35 & 12.02 \\
\hline 华夏 & 886 & 30.75 & 83.76 & 1. 67 & 31.45 & 11.36 \\
\hline
\end{tabular}


续表 216 家上市商业银行的原始数据

\begin{tabular}{|c|c|c|c|c|c|c|}
\hline & \multicolumn{3}{|c|}{ 人均净本科以 } & \multicolumn{3}{|c|}{ 不良贷 流动性 资本充 } \\
\hline & 网点数 & 利润 & 上学历 & 款率 & 比例 & 足率 \\
\hline & X6 & X7 & 占比 & X9 & X10 & X11 \\
\hline & & (万） & $\begin{array}{c}X 8 \\
(\%)\end{array}$ & $(\%)$ & $(\%)$ & $(\%)$ \\
\hline 光大 & 1122 & 44.52 & 81.95 & 1.60 & 63.18 & 10.8 \\
\hline 中信 & 1424 & 47.42 & 87. 14 & 1.69 & 25 & 11.98 \\
\hline 北京 & 501 & 91.75 & 81.00 & 1. 27 & 50.1 & 12.20 \\
\hline 南京 & 162 & 60.10 & 90.00 & 0.87 & 47. 71 & 13.71 \\
\hline 宁波 & 314 & 45.77 & 94.77 & 0.91 & 44.95 & 12.25 \\
\hline
\end{tabular}

首先需对逆向指标成本收入比 $X 4$ 和不良贷款率 $X 9$ 通 过 $B i=1-X i$ ( $B i$ 为调整后的指标值, $X i$ 为调整前的指标值) 来调整。

\section{4. 因子分析过程}

\section{1. 统计检验是否适合利用因子分析法}

使用 SPSS 23 统计软件对原始数 据计算相关系数矩阵并进行统计检 验。在正向化数据的基础上得出的相 关系数矩阵和检验结果。知道 KMO 统 计量 $=0.56>0.5$, Bartlett 球形度检验 卡方统计量的 $\mathrm{Sig}<0.01$, 由此否定了 相关矩阵为单位矩阵的原假设, 即各 变量之间存在着显著地相关性, 适宜 因子分析。

\section{2. 提取因子}

由总方差解释图可知, 变量相关 系数矩阵的四个特征值: 5.007 , $1.803 ， 1.257,1.002$, 都满足因子分 析变量特征值大于 1 的第一个标准。 并且, 前四个因子总体方差为 82. 445\%, 满足因子分析累积贡献率大 于 $81 \%$ 的第二个标准。综合上述, 我们 可以认为前四个因子基本包括了所有 评价指标要反映的内容。

\section{3. 建立因子载荷矩阵}

采用最大方差法旋转之后的因子 载荷矩阵。设 $F$ 为提取出的主因子, 上述四个因子可表示为 F1、F2、F3、 $\mathrm{F} 4$ 。由旋转后的成分矩阵图可知, 第 一主成分 F1 在 X5, X1, X6 的载荷较 大, 解释为金融科技创新、金融业务 创新的综合因子。第二主成分 F2 在 $\mathrm{X} 11, \mathrm{~B} 9$ 的载荷较高, 看成金融风险管 理创新的因子。第三主成分 F3 在 B4, X7 的载荷较大, 视为金融业务创新和 金融人力资源管理创新的综合因子。 第四主成分 F4 在 X10, X8 的载荷较 大, 视为金融风险管理创新和金融人 力资源管理创新的综合因子。

\section{4. 计算各因子得分及综合评价得分并 排序}

运用回归法计算出的因子得分系 数矩阵。由成分得分系数矩阵, 四个 主因子的表达为:

$\mathrm{F} 1=0.238 \mathrm{X} 1+0.066 \times 2-$

$0.156 \times 3+0.124 \mathrm{~B} 4+0.229 \times 5+0.143 \times 6-$

$0.084 \times 7-0.162 \times 8-0.169 \mathrm{~B} 9-$

$0.004 \times 10+0.088 \times 11$

$\mathrm{F} 2=-0.059 \times 1-0.537 \times 2+0.064 \times 3-$

$0.094 \mathrm{~B} 4-0.069 \times 5+0.108 \times 6+0.058 \times 7-$

$0.054 \mathrm{X} 8+0.386 \mathrm{~B} 9+0.024 \mathrm{X} 10+0.360 \mathrm{X} 11$

$\mathrm{F} 3=-$

0. $253 \mathrm{X} 1+0.127 \times 2+0.047 \times 3+0.701 \mathrm{~B} 4+0$. $155 \times 5-$

$0.129 \times 6+0.368 \times 7+0.065 \times 8+0.054 \mathrm{~B} 9-$

$0.038 \times 10+0.081 X 11$

$\mathrm{F} 4=-0.127 \times 1-0.007 \times 2-0.371 \times 3-$

$0.020 \mathrm{~B} 4+0.012 \times 5-0.070 \times 6-$

$0.068 \times 7+0.084 \mathrm{X} 8+0.021 \mathrm{~B} 9+0.872 \times 10+$

0. 040X11

根据总方差解释表中 4 个综合因 子方差的贡献率，可对四个公因子的 得分进行加权求和, 权数取其方差贡 献率作为权重, 四个旋转后公因子的 方差贡献率依次为 $45.520 \%$, 
16. $394 \% ， 11.423 \% ， 9.109 \%$ 于是可以 构造出 2016 年 16 家上市银行各因子 得分、综合得分和平均排名。（见表

3)

$\mathrm{F}=$

45. $520 \% \mathrm{~F} 1+16.394 \% \mathrm{~F} 2+11$. $423 \% \mathrm{~F} 3+9.109 \% \mathrm{~F} 4$ ）/82. 445\%

表 3 上市银行各因子得分、综合得分和排名 \begin{tabular}{|l|}
\hline 主成排主成排主成排主成排 综合F 排 $_{\text {分 }}$ \\
\hline 分分 $\mathrm{F} 2$ 名分 3 名分 4 名
\end{tabular}

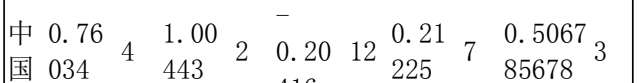

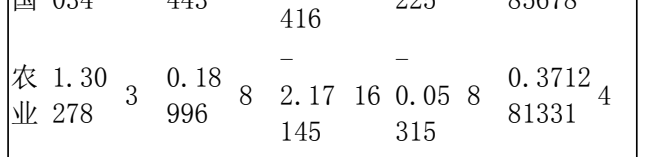

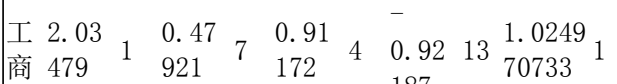
$\begin{array}{llllllll}\text { 建 } 1.42 & & 0.97 & & 0.44 & & - & 0.10 \\ \text { 设 } 247 & 2 & 405 & 3 & 027 & 8 & \begin{array}{l}0.8479 \\ 434\end{array} & 81813\end{array}$ $\begin{array}{lllllllllll}\text { 民 }^{-} & & - & - & & - & & - \\ \text {生 } & 0.00 & 7 & 1.49 & 16 & 0.19 & 11 & 0.16 & 11 & 0.2846 & 13\end{array}$

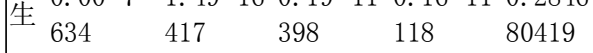

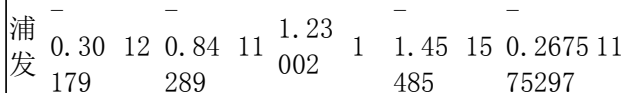

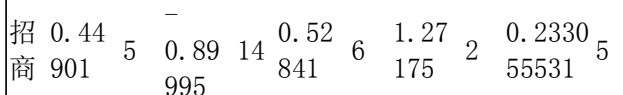

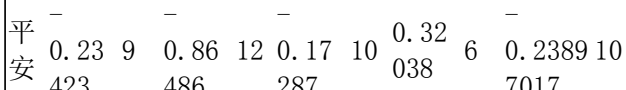

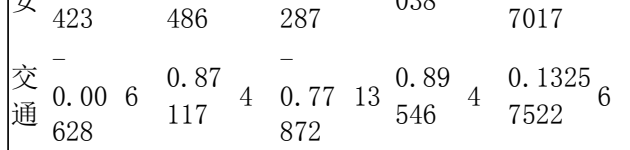

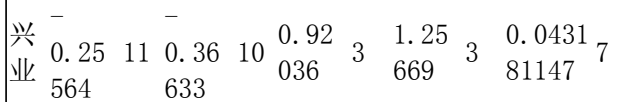

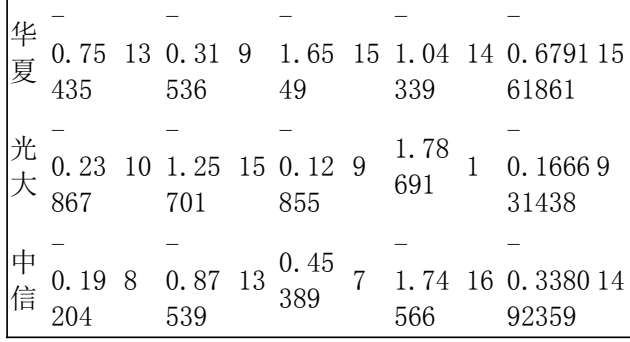
续表 3 上市银行各因子得分、综合得分和排名

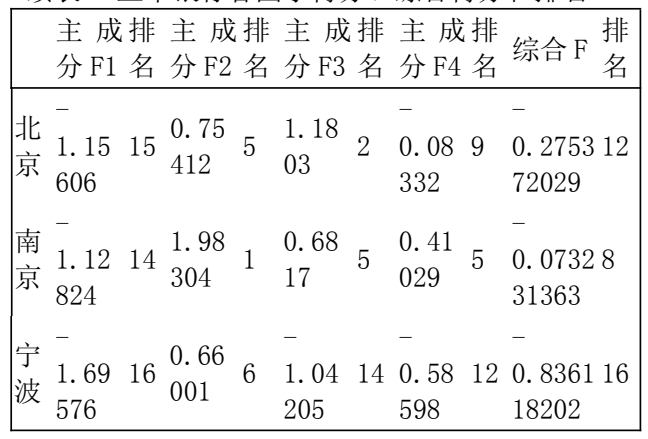

\section{5. 评价结果分析}

从上面的分析和计算结果可以看 出, 不同银行对应的每个因子的排名 与最后的综合排名并不完全具有一致 性, 而且有些银行的单项排名与其综 合排名还有很大差距, 说明所选取商 业银行的金融创新力水平存在着明显 的差异, 由此可以得出以下结论:

（1）从第一个主成分 F1 来看, 我国 国有控股商业银行的排名靠前, 工商 银行排名第一, 股份制银行招商银行 排名第一。2016 年, 我国 4 家国有控 股商业银行的手续费及佣金净收入合 计达 4127.81 亿元, 占 16 家上市商业 银行手续费及佣金净收入的 53\%，说明 四大行非利息收入高，科技、规模实 力雄厚, 同 BAJT 合作会产生巨大的金 融效应。

（2）从第二主成分 F2 来看, 南京银 行、中国银行、建设银行、交通银行 和北京银行排在前面。南京银行和北 京银行的不良贷款率都较低; 五个银 行的资本充足率基本高于 $13 \%$ 。城市商 业银行主要客户群是中小微企业, 信 贷特点是 “短、小、急、频” , 受互 联网金融的技术溢出效应的吸引能力 大于国有银行，不良贷款率反而低。

(3) 从第三主成分 F3 来看, 前五名 分别是浦发银行、北京银行、兴业银 行、工商银行和南京银行。浦发银行 成本收入比最低, 北京银行的人均净 
利润最高。对国有银行而言，股份制 银行和城市商行后来居上, 更注重创 新, 金融创新速度快。从人均净利润 的指标来看, 城市商业银行的人均利 润高于股份制商业银行，而股份制商 业银行的人均利润高于国有银行。国 有银行作为传统商业银行, 组织架构 较为臃肿, 员工层次复杂; 创新力度 不够, 业务流程繁杂效率低, 导致了 人均净利润较低的现实。

(4) 从第四主成分 F4 来看, 排名靠 前都是股份制银行和城市商业银行。 流动性比例大于 $50 \%$ 都是股份制银行和 城市商行，股份制银行和城市商业银 行信贷业务的来源主要是长尾客户, 流动性需求比较大; 并且其员工本科 以上学历占比都要高于国有银行; 这 与国有商业银行较重的历史负担有 关, 人员层次参差不齐, 学历层次普 遍有待提升。

在综合实力上, 中国工商银行、 中国建设银行、中国银行和中国农业 银行的排名靠前; 招商银行的综合排 名第五, 在中小银行中的排名是最好 的。我国上市国有商业银行的整体水 平要优于上市股份制商业银行的整体 水平, 上市股份制商业银行的整体水 平要优于城市商业银行的整体水平。

\section{5. 促进我国上市商业银行金融创新的 对策建议}

\section{1. 金融业务创新}

加大中间业务和表外业务创新是 商业银行增加盈利、扩大市场份额、 推进业务综合化的有效途径。当前银 行的中间业务应在做好传统品牌业务 的同时, 积极开展服务与产品的创 新。要依靠科技力量, 根据目标客户 群体的需求制定下相应的理财产品, 且根据客户群体的差异提供多样化的
金融产品，提升自身服务水平和质 量。

\section{2. 金融科技创新}

提高信息科技支撑能力，对信息 科技的投入是商业银行不可回避的战 略性问题, 可以说银行所有业务活动 都依赖于信息科技的支撑。因此，未 来商业银行要积极主动加大对信息科 技的投入, 每年拿出税前利润的一定 比例作为科技建设资金，适应市场环 境的变化, 提升经营管理的信息化、 数字化水平, 提高部门协作效率, 加 强金融科技等业务的拓展，进一步提 升商业银行金融创新能力。

\section{3. 金融风险管理创新}

金融创新在规避风险的同时又会 产生新的风险, 怎样进行风险管控成 为重中之重。首先在新产品的审批中 要进行科学分类, 加强风险评估, 在 产品推出后进行跟踪监督; 其次, 对 各种表外业务的潜在风险和各传统信 贷业务的现实风险要平等对待; 最 后, 创新业务的营销与管理要分开, 遵循风险管理内部分工制衡的原则, 能防止以往创新业务中出现的风险。

（四）金融人力资源管理创新

银行业的竞争实质上金融创新人 才的竞争。创新人员素质的高低直接 决定了金融创新的质量和效率。首 先, 商业银行应通过外部引进和内部 培养相结合的方式，建立一支专业 化、结构合理的复合型金融创新队 伍, 为金融创新提供强有力的智力支 持。同时要建立健全金融创新的激励 约束机制, 积极培育 “激励创新” 的 企业文化，促进金融创新工作的高效 开展。 


\section{6. 结论}

综合上述, 虽然国有银行在整体 实力上更强，但是中小银行在流动 性, 人力资源和人均创利具有潜力。 各银行需发挥自身的优势, 扬长避 短; 同业之间取长补短, 差异化互 补; 跨行业间合作共赢, 商业银行需 要尽快摆脱同质化竞争和收入结构单 一的状况, 在防控金融风险的基础 上, 实现产品和服务的转型与升级。 随着我国金融体制改革不断深化, 要 以金融监管为重点, 防范系统性风险 为底线, 加快相关法律法规建设, 加 强宏观审慎管理和微观市场监管, 加 强互联网金融监管。

\section{参考文献}

[1]曹蒸蒸. 我国商业银行金融创新力 评价 $[\mathrm{J}]$. 金融理论与实践, 2009, (11) : 85-88.

[2]刘铁锤. 论国家控股商业银行的金 融创新 $[\mathrm{J}]$. 经济研究导刊, 2013, (23) : 204-205.

[3] 令伟锋, 李杰. 我国商业银行金融 创新能力分析 $[\mathrm{J}]$. 商场现代化, 2008, (35) : 92.

[4] 马婧宁. 国内上市商业银行金融创 新能力评价研究 [D]. 东北师范大 学, 2015.

[5]任婉璐. 国有银行金融创新评价体 系指标的实证分析 $[\mathrm{J}]$. 宜春学院 学报, 2015.

[6]司彩丽. 我国上市商业银行金融创 新能力评价 [D]. 合肥工业大学, 2010.

[7] 孙彦骊. 浅谈我国商业银行金融创 新 $[\mathrm{J}]$. 安徽工业大学学报 (社会科 学版)，2011，28(02)：16-17.

[8] 肖科, 夏婷. 国有商业银行金融创 新力的评价 $[\mathrm{J}]$. 统计与决策, 2006, (21) : 105-106.
[9]张健. 黑龙江省区域金融创新能力 评价及提升对策 [D]. 哈尔滨工程大 学, 2008. 